\title{
Exhaled nitric oxide using end-tidal concentration during methacholine challenge
}

\begin{abstract}
Increased nitric oxide in exhaled gas in patients with asthma is thought to reflect the severity of airway inflammation and perhaps airway reactivity. Several studies attempted to identify a relationship between exhaled NO levels and airway reactivity or severity of airway inflammation for the purpose of finding out if exhaled NO could be used in place of pulmonary function testing and airway provocation test. Unfortunately, the relationship is not always evident. In recent years, it has become clearer that exhaled NO becomes elevated primarily in atopic asthma patients. All previous studies have used the single vital capacity slow exhalation maneuver to measure ENO (FeNO50). This method is subject to errors because it requires patient cooperation, is flow rate dependent and adds more stress on the patient. Recently, we showed that end tidal NO concentration (NOet) is clinically relevant, are much easier to measure and are not subject to flow variation or patient cooperation. We used NOet (ppb) measurement before and during methacholine challenge in patients with symptoms of mild, persistent asthma. In addition we calculated NO production (NOpr) (n mole/min) to correct for possible changes in ventilation. Eleven patients exhibited hyper-responsiveness to methacholine (responders) and 17 exhibited negative response (non-responders). The responders had a slightly higher NO level than the non-responders whether expressed inppb or in $\mathrm{nn} \mathrm{mol} / \mathrm{min}$ but did not reach statistical. Significance: NO et values were $15.1 \pm 2.4 \mathrm{ppb}( \pm \mathrm{SE})$ and $11.7 \pm 2.3 \mathrm{ppb}$ respectively and NOpr values were $5.83 \pm 0.86 \mathrm{n} \mathrm{mol} / \mathrm{min}$ and $5.12 \pm 1.13 \mathrm{nnmol} / \mathrm{min}$ respectively.
\end{abstract}

There was no correlation between baseline NOet levels and the change in FEV1 in the responders. Furthermore, there was no consistent change in NOet or NO pr levels during broncho constriction with methacholine. We conclude that although exhaled NO levels may serve as a helpful adjunct in treatment of asthma, its level alone does not reflect severity of the disease in mild asthmatics nor the airway responsiveness to methacholine. Exhaled NO was estimated using the average $\mathrm{NO}$ value at end expiration during normal tidal breathing. This method was quicker, repeatable and much easier on the patients and none of the patients objected to doing the measurement. There was no need to put patients through the complicated single full vital capacity slow exhaled maneuver to obtain this information.
Volume 2 Issue 5 - 2015

\author{
Tawfic S Hakim,' George Cremona, ${ }^{2}$ \\ Devanand Mangar, ${ }^{3}$ Enrico M Camporesi ${ }^{3}$ \\ 'Sleep Apnea Treatemnt Unit, Pheonix, USA \\ ${ }^{2}$ Ospedale San Raffaele, Pulmonary Division, Milan, Italy \\ ${ }^{3}$ Teamhealth Anesthesia, Anesthesiology, Tampa General Hospital, \\ Tampa, USA
}

\begin{abstract}
Correspondence: Tawfic S Hakim, Sleep Apnea Treatment Unit, I0443 N Cave Creek Rd, Suite I I0, Phoenix, Arizona
\end{abstract} 85020, USA, Tel (602) 944-0847, Email salthakim@yahoo.com

Received: April 08, 2015 | Published: April 16, 2015

Keywords: nitric oxide, exhaled, end tidal, asthma, methacholine, airways

Abbreviations: FeNO50, exhaled nitric oxide measured using

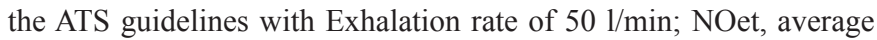
end tidal nitric oxide concentration from 5-7 breaths; NOpr, average nitric oxide production in nmol/min; Mch, methacholine; FEV1, forced expired volume in $1 \mathrm{sec}$; PD20, dose of Mch that elicited 20\% reduction in FEV1; FVC, forced vital capacity; PEF, peak expiratory flow; sGAW, specific airway conductance; $\mathrm{NO}$, nitric oxide

\section{Introduction}

Asthma is characterized by airway inflammation and airway hyper-responsiveness. Exhaled NO is thought to be a useful marker of airway inflammation because asthmatic patients exhibit higher levels of exhaled NO than normal subjects ${ }^{1-3}$ and because treatment with corticosteroids blunts such elevation in exhaled NO.,4 The level of nitric oxide in exhaled gas in patients with asthma has been the subject of many studies designed to elucidate its significance in relation to airway inflammation and severity of the symptoms. ${ }^{2,5,6}$ Anti-inflammatory treatment with corticosteroids lowers NO levels in the exhaled gas and alleviates the symptoms in patients with asthma. ${ }^{7-9}$ It has become clearer that NO levels in the exhaled gas involves a complicated series of events and depends on the severity of inflammation, location of inflammation and type of inflammatory cells involved. ${ }^{10}$ It remains unclear if exhaled NO bears any relationship to pulmonary function, airway inflammation or airway reactivity in all asthmatics. ${ }^{11}$ Taylor et al. ${ }^{12}$ suggested that in mild asthmatics, endogenous NO neither protects against nor contributes to the processes underlying airways responses to inhaled allergens. It is clear that exhaled NO is not elevated in all asthma patients. ${ }^{4}$ In most studies, exhaled $\mathrm{NO}$ was measured using the single deep breath maneuver (FeNO50) following the ATS guidelines. ${ }^{13,14}$ Exhaled NO is not to always elevated in asthma patients and maybe specific to atopic allergic asthma patients and involves a special type of inflammatory cells. ${ }^{410}$ Donohue et al. ${ }^{4}$ suggested that exhaled NO measurement may be useful primarily for identifying asthma patients who will respond or will not respond to corticosteroids therapy. Nevertheless, some studies support the notion that neither FeNO50 values nor the changes during corticosteroid therapy can be reliably used to manage patients with asthma.

Airway hyper-responsiveness is a hallmark of asthma and is often used as an indicator of asthma severity. Different pharmacologic 
agents (such as methacholine, histamine, AMP) or specific allergens are used to assess reactivity of the airways. Since exhaled nitric oxide and airway reactivity are associated with asthma, the notion that exhaled NO could replace airway challenge tests have been suggested..$^{15}$ However, sensitivity to broncho-provocation, does not always coincide with the level of exhaled NO, perhaps because some agents cause broncho constriction by direct action on smooth muscle, while other cause broncho constriction via release of mediators from inflammatory cells. ${ }^{16,17}$ Guan ${ }^{18}$ concluded that exhaled NO correlates to Mch response only in some patients while Prieto et al., ${ }^{19}$ suggested that a topy is not the only determinant of increased ENO detected in patients with asthma and that responsiveness to AMP is a better marker for assessing airway inflammation than methacholine. Furthermore broncho constriction may affect exhaled NO via changes in ventilation distribution and such changes may need to be taken into consideration and may represent a different biological phenomena. ${ }^{6,20}$ This complicated matter is further confounded by the method that was used to measure exhaled NO. Exhaled NO was usually measured using the single vital capacity exhaled breath as suggested by the ATS guidelines. ${ }_{13,14}$ Such test is flow dependent and requires patient's cooperation and repeated spirometric maneuvers that may be too stressful for the patient and may affect exhaled NO for several hours. ${ }^{21}$

Our goal was to measure exhaled NO using end tidal value (NOet) which is independent of ambient $\mathrm{NO}$ and does not require patient cooperation. ${ }^{22}$ Furthermore NOet measurement is much easier and quicker than the single vital capacity maneuver (FeNO50). The goal was to see if NOet is more repeatable with a better relationship to pulmonary parameters or airway responsiveness.

\section{Materials and methods}

Adult patients (20-62yrs) were recruited for this study after being referred to our Pulmonary Function Laboratory for evaluation for asthma including methacholine (Mch) challenge. The study was approved by the Institutional Review Board and a consent form was signed by all patients. All patients were suspected of having asthma on the basis of symptoms of cough, wheezing or chest discomfort. None of the patients had symptoms of sinusitis, recent upper respiratory tract infection, or evidence of poor dental hygiene. All but two were nonsmokers and 2 were ex-smokers and were stable at the time of the test. These patients were not tested for specific allergens. Pulmonary function Testing Protocol: All patients were asked not to take any medication on the morning when the test is being administered. Spirometry and plethysmography (Med graphics 1085, Medical Graphics Corp, St Paul, MN) were completed prior to airway challenge. The test consisted of spirometry during baseline, after inhalation of saline aerosol, following administration of each dose of Mch and after inhalation of bronchodilator. Plethysmography was done during baseline, after the last dose of Mch and after bronchodilator.

The concentrations of Mch used were $0.025,0.25,2.5,10$ and $25 \mathrm{mg} / \mathrm{ml}$. Methacholine was delivered by a DeVilbiss nebulizer and dosed with a Rosenthal-French nebulization dosimeter (Laboratory for Applied Immunology, model 2A, Baltimore). Inhalation of Mch was initiated at FRC with the subject taking five deep breaths. The dose of Mch was increased until at least a $20 \%$ reduction in FEV1 was obtained (considered responder) or until all doses were tested (considered non-responders). Once a $20 \%$ decrease in FEV1 was accomplished higher doses were not tested in the responders. The spirometry was done $3 \mathrm{~min}$ after delivery of each dose. After the last dose of Mch was delivered and measurements were completed, the subject received inhaled beta-agonist and five minutes later the measurements were repeated.

Nitric oxide measurement after completing each step in the pulmonary function testing, the subject was asked to breathe through a mouth piece for measurement of nitric oxide using a fast response chemiluminescence analyzer (Sievers NOA model 270B, Boulder, $\mathrm{CO})$. Gas was sampled into the analyzer from a port near the mouth piece at $400 \mathrm{ml} / \mathrm{min}$. The signal from the analyzer was fed into a computer for continuous breath by breath recording. The analyzer was calibrated daily by introducing air with zero NO from a gas cylinder and from a mixed gas bag containing $248 \mathrm{ppb} \mathrm{NO}$ which was prepared from a certified gas tank containing 1424ppb (ML gas, Syracuse, NY). Room air NO was recorded prior to each measurement and the zero was verified between the measurements. The test consisted of normal tidal breathing through a Rudolph 3 way valve. The subject inhaled room air and exhaled through a pneumotach for measurement of minute ventilation. End expiration was identifies from the pneumotach recording. A breath by breath inspiratory and expiratory concentration of the NO was recorded continuously during quiet breathing for $5-7 \mathrm{~min}$. The average end tidal NO values (NOet) from 7 to 10 breaths were calculated to represent end tidal $\mathrm{NO}$ concentration (NOet). NOet was shown to be independent of ambient NO concentration. ${ }^{22}$ In order to account for changes or differences in minute ventilation, the product of $\mathrm{NO}$ concentration and minute ventilation was used as an estimate of $\mathrm{NO}$ production (NOpr) in nmole/min.

Statistical analysis of the results was accomplished using ANOVA for repeated measures and post hoc t-test (Bonferroni test) for changes in NOet and NOpr. Differences in NOet and NOpr between the two groups of patients were tested using a non-paired t-test. All results are expressed as means \pm SEM. Relationships between two parameters were determined using regression analysis. $\mathrm{P}$ values $<0.05$ were considered significant.

\section{Results}

Thirty one patients were recruited in this study. Three patients were excluded from the analysis because they were receiving inhaled corticosteroid therapy. Of the remaining 28 patients, 11 responded to Mch challenge and 17 did not respond. Table 1 lists demographics and baseline respiratory parameters in the two groups, responders (R) and non-responders (NR). Baseline FEV1 or FEV1/FVC were not significantly different between the two group, but peak expiratory flow was significantly lower in responders $(p<0.05)$. PD20 was $3.36 \pm 0.49 \mathrm{mg} / \mathrm{ml}(\mathrm{mean} \pm \mathrm{SEM})$ in the responders compared to the non-responders.

Nitric oxide concentration varied widely in range in both responders and non-responders regardless of the method of expressing NO values (Figure 1). Responders had NOet of $15.1 \pm 2.4 \mathrm{ppb}$, compared to $11.7 \pm 2.3 \mathrm{ppb}$ in non-responders (not statistically significant). We also calculated NO production (NOpr) to account for possible differences or changes in minute ventilation. At baseline, NOpr was $5.83 \pm 0.86$ $\mathrm{nmol} / \mathrm{min}$ in responders and $5.12 \pm 1.13 \mathrm{nmol} / \mathrm{min}$ in non-responders. The values were generally higher in responders but did not reach a statistically significance level $(\mathrm{p}=0.07)$. 
Table I Demographics and baseline respiratory values (mean \pm SE)

\begin{tabular}{|c|c|c|c|}
\hline & $\begin{array}{l}\text { Responders } \\
(n=I I)\end{array}$ & $\begin{array}{l}\text { Non-responders } \\
(\mathrm{n}-17)\end{array}$ & P Value \\
\hline Age, yrs & $36.5 \pm 5.6$ & $40.3 \pm 3.1$ & NS \\
\hline Male/Female & 5-Jun & I0-Jul & \\
\hline FVC, \% predicted & $86.7 \pm 4.2$ & $93.2 \pm 3.4$ & NS \\
\hline FEVI, \% predicted & $85.2 \pm 5.2$ & $92.3 \pm 3.4$ & NS \\
\hline FEVI/FVC, \% predicted & $82.6 \pm 0.8$ & $82.1 \pm 1.3$ & NS \\
\hline PEF, \% predicted & $80.5 \pm 3.3$ & $102.8 \pm 7.3$ & NS \\
\hline sGAW, \% predicted & $74.7 \pm 11.2$ & $101.3 \pm 10.6$ & NS \\
\hline $\begin{array}{l}\text { Methacholine PD20, } \\
\mathrm{mg} / \mathrm{ml}\end{array}$ & $3.36 \pm 0.49$ & $>25$ & $P<0.05$ \\
\hline
\end{tabular}

FVC, forced vital capacity; FEVI, forced expired volume in I sec; PEF, peak expiratory flow; sGAW, specific airway conductance
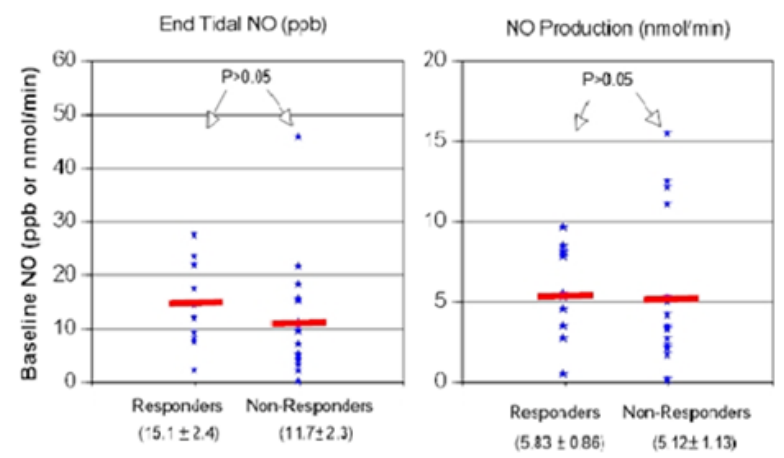

Figure I $N=57$; Epidemiological distribution of the pathological fractures, traumatic fractures, and nonunion.

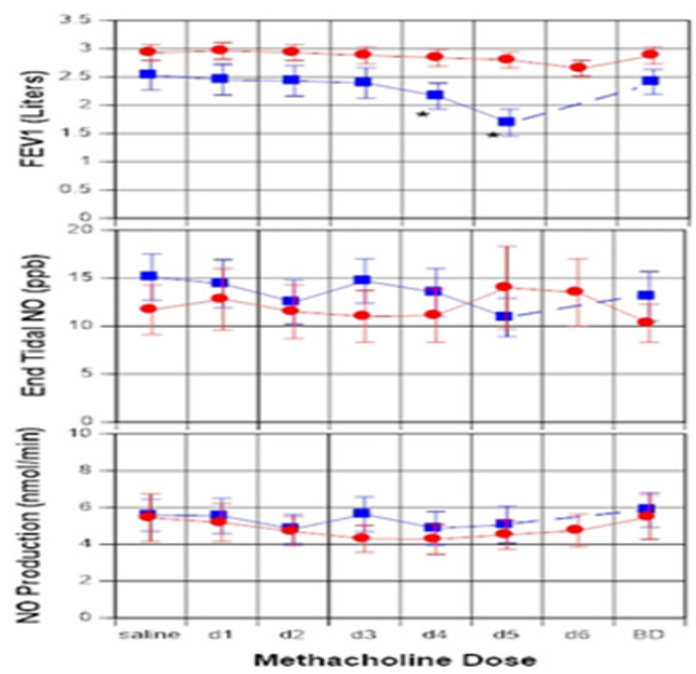

Figure 2 Mean exhaled nitric oxide $( \pm S E)$ before and after each dose of methacholine challenge and after bronchodilator. The concentrations of methacholine used for the challenge were $0.025,0.25,2.5,10$, and $25 \mathrm{mg} / \mathrm{ml}$. There was no effect on exhaled nitric oxide during methacholine challenge in either group whether expressed in $\mathrm{ppb}$ or in $\mathrm{nmol} / \mathrm{min}$.
Figure 2 illustrates the changes in FEV1 in the two groups following administration of successive doses of Mch and after bronchodilation. FEV1 in the responders (Figure 2A) fell $20 \%$ or more after the third or fourth dose of Mch (PD20 $=3.36 \pm 0.49 \mathrm{mg} / \mathrm{ml})$. In contrast, FEV1 did not change significantly in the non-responders after the highest dose of Mch. FEV1 was significantly smaller after the highest dose compared to baseline value $(\mathrm{p}<0.05)$. Figures $2 \mathrm{~B}$, Figure $2 \mathrm{C}$ show the changes in exhaled NO expressed inppb or in $\mathrm{nmol} / \mathrm{min}$. Despite the marked difference between the two groups in FEV1 response, the changes in NOet and NOpr were not significant at any dose of Mch with the exception following bronchodilation in the responders group $(p<0.05)$. Usually patient's maintained steady NO levels during the course of the test.

Figure 3 shows the relationship between maximum decrease in FEV1 with methacholine and NO values at baseline. The maximum decrease in FEV1 appears to barely correlate to NOet levels in the responders (Figure 3), with a poor correlation coefficient $(r<0.4)$. The slope was flatter in the non-responders but was not statistically different from the slope in responders. The same conclusion was reached from the relationships using NOpr (Figure 4); not significantly different between the 2 groups.
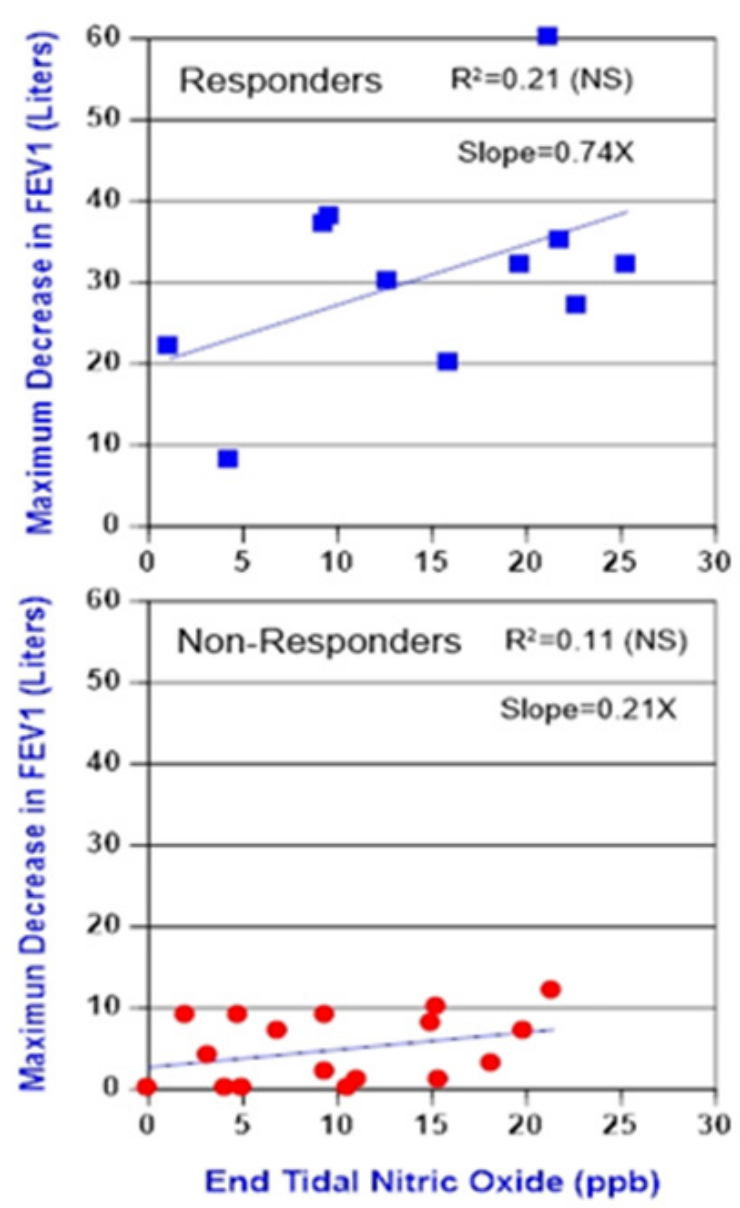

Figure 3 Relationship between exhaled nitric oxide (ppb) at the beginning of the test and the maximum response in FEVI in the 2 groups. The linear relationship was not statistically significant in either group. The slopes and R2 values are given. 

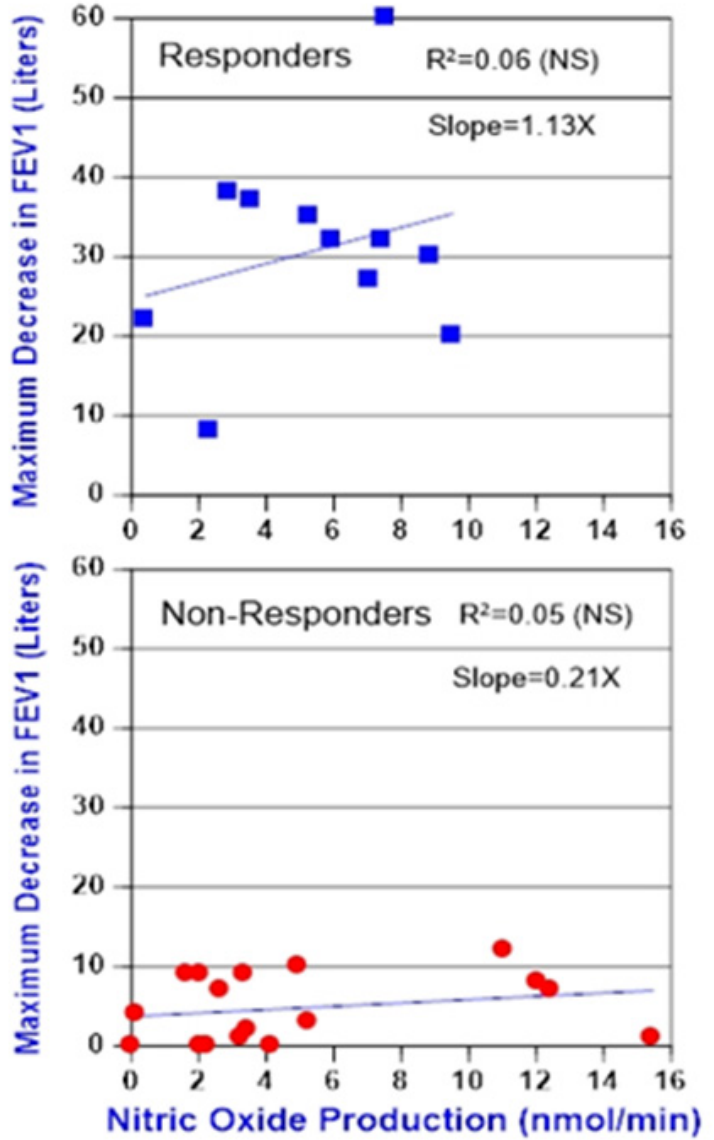

Figure 4 Relationship between exhaled nitric oxide ( $\mathrm{nmol} / \mathrm{min}$ ) at the beginning of the test and the maximum change in FEVI.The linear relationship was not statistically significant in either group. The slopes and R2 values are given.

\section{Discussion}

In this small population of asthma patients, we measured exhaled NO using end tidal value (NOet) as described previously ${ }^{22}$ and found a poor relationship between exhaled NO and airway reactivity. Although there was a clear difference in FEV1 between the responders and non-responders, there was no significant difference in NOet. Furthermore, our results show that broncho constriction did not affect NOet significantly. There was a minimal correlation between changes in FEV1 and NOet. Increased NO in asthmatic patients is attributed to an increase in inducible nitric oxide syntheses expression in many cells throughout the lungs. ${ }^{5}$

Therefore it is not unreasonable to expect NO to be elevated throughout the lungs of asthmatics; but predicting the response to bronchial challenge is more complicated. The issue is how to assess changes in exhaled NO and perhaps identify changes in NO in the peripheral regions versus changes in the central regions. Many studies have measured exhaled NO using the single deep breath maneuver (FeNO50) according to ATS guidelines. ${ }^{13,14}$ The difficulty with such measurement has been discussed in length previousl ${ }^{22}$ and primarily is attributed to the dependence of the measurement on the flow rate ${ }^{23}$ and on patient cooperation. The measurement becomes more confounded during broncho constriction. It is not surprising that published results on FeNO50 during baseline and during methacholine challenge produced conflicting data. Most studies have reported only modest relationships between PD20 and FeNO50. ${ }^{11,24-26}$ Further complication could arise if the exhaled maneuver is influenced by changes in gas distribution due to broncho constriction ${ }^{27}$ or if expiratory flow rates exceed $150 \mathrm{ml} / \mathrm{sec}^{28}$ One study ${ }^{19}$ suggested a relationship between FeNO50 and airway reactivity to AMP response (albeit marginal), but not to methacholine. Another study ${ }^{17}$ did not find a significant correlation between FeNO50 and airway reactivity either with AMP or methacholine. Allergen induced increase in FeNO50 has also been reported by Ricciardolo et al., ${ }^{29}$ in atopic asthma patients but such a change usually is delayed occurring after a few hours. Taylor et al., ${ }^{12}$ suggested that in mild asthmatics, endogenous NO neither protects against nor contributes to the processes underlying airways responses to inhaled allergens (they used NOS inhibitor and did not measure exhaled NO).Thus most studies find little relationship between FeNO50 and airway reactivity. Our results using the simple method of measuring end tidal NO value support such conclusions. Some studies reported slightly different results; Dupont et al., ${ }^{8}$ and Cirillo et al., ${ }^{16}$ found airway hyper-responsiveness to histamine and methacholine associated with increased levels of exhaled NO in asthmatic subjects. Dupont's study involved mild asthmatics which lead them to speculate that NO levels in the exhaled gas could be used to identify asthmatic subjects who are corticosteroid naive. ${ }^{8}$ The measurements were taken at a very low expiratory flow rate of $20 \mathrm{ml} / \mathrm{s}$ against a very high resistance of $20 \mathrm{~cm} \mathrm{H} 2 \mathrm{O}$ that could have biased the results. Our patients also had mild asthma and were corticosteroid naive, however, in contrast to Dupont's results, our data did not shows a correlation between exhaled nitric oxide level and severity of the disease as indicated from PD20 or from FEV1 during baseline. The reason for such difference may be due to the different agent used for the challenge and that they used FeNO50 which is subject to errors compared the NOet used in our study. Cirillo et al., ${ }^{16}$ reported a correlation between airway reactivity and FeNO50, although too low to be useful for predicting airway reactivity.

There may be other factors that could affect exhaled NO during broncho provocation such as site of broncho constriction and ventilation heterogeneity. These factors were not examined in our study but are worth discussing briefly. Using impulse oscillometry different patterns of response were observed following methacholine challenge; ${ }^{30}$ broncho constriction responses involved primarily peripheral airways. Similarly, CT imaging has demonstrated greater changes in peripheral airways after methacholine challenge in asthmatics. ${ }^{31}$ Other studies using multiple breath nitrogen washout and imaging ${ }^{32}$ have shown an increase in ventilation heterogeneity in individuals with hyper reactivity to methacholine which appeared to be independent of changes in airway resistance..$^{33}$ Modelling studies indicate that the most marked effect of airways constriction on FeNO50 is most likely to occur in generations $10-15$ and that constriction in smaller airways is likely to increase FeNO50 due to interference with the NO back diffusion effect. ${ }^{34}$ Ventilation heterogeneity has been reported as a major predictor of airway reactivity independently of the degree of inflammation, ${ }^{35}$ while airway smooth muscle contraction may be the major cause of airway reactivity. ${ }^{36}$ Indeed, agents used for the challenge can yield different results; an increase in exhaled NO was observed with allergen but a decrease was observed after methacholine challenge. ${ }^{37}$ Based on our results, we cannot make conclusions regarding role of ventilation and broncho constriction heterogeneities, but it is important to keep those factors in mind when discussing exhaled NO values. 
The principle finding in this study is the lack of a clear relationship between NO levels in the exhaled gas and airway responsiveness to methacholine challenge in patients with mild persistent asthma. The results suggest that a patient with mild asthma having normal or elevated exhaled NO do not predict airway hyper-responsiveness. There is no doubt that nitric oxide in the exhaled gas of asthma patients tends to be elevated compared to control subjects ${ }^{1-3}$ but there is always a wide range and large overlap that would preclude a strong conclusion. It would seem that, if anything NO could alleviate airway responsiveness, because of the bronchodilatory effects of NO. Thus NO levels, if any, should correlate negatively to airway reactivity in the presence of airway inflammation. These findings, however, have not been confirmed in humans. ${ }^{37,38}$ On the contrary, asthmatics tend to have increased airway responsiveness, despite having elevated NO. Treatment of asthma patients with inhaled steroids attenuates airway inflammation, lowers NO level to a normal value, improves the symptoms, ${ }^{3,5,9}$ but does not always diminish bronchial hyper reactivity. ${ }^{8}$ Therefore it appears that bronchial reactivity and NO production are independent biological phenomena. ${ }^{12}$ Although, we found a trend between the methacholine challenge and the NO in the exhaled gas, the relationship was marginal. Bronchial reactivity to methacholine is commonly used to diagnose asthma. ${ }^{8,39}$ However, methacholine is a nonspecific agonist that causes broncho constriction by direct action on the airways. ${ }^{40,41}$ Histamine challenge appears to correlate better to NO in the exhaled gas perhaps because it acts indirectly. ${ }^{8}$ Thus, it is possible that airway response may depend on the size of airways which are affected and the state of airway caliber due to inflammation or by exudates.

Despite different limitations which affect the measurement of exhaled NO, the simple method which we used to assess nitric oxide led to similar conclusions as previous studies that used the more complicated "standard" method. Most previous studies have used the single vital capacity maneuver according to ATS guidelines. ${ }^{13,14}$ The ATS guidelines method is subject to variability by the size of breath, the time of breath hold, the expiratory resistance and rate of exhalation. The standard measurement flow rate of $50 \mathrm{ml} / \mathrm{sec}$ is somewhat arbitrary and has the effect of conditioning expired air with a longer time in proximal non expansible airways with a resultant bias of the final measurement towards a specific compartment. Current guidelines advocate the use of expiratory flow resistance of over $5 \mathrm{~cm} \mathrm{H}_{2} \mathrm{O}$ which may affect ventilation heterogeneity and may alter functional residual capacity. Additionally, the single breath maneuver is difficult to perform by some patients and in children. We have used the nitric oxide concentration at end expiration during normal breathing as representative of lung nitric oxide level in the peripheral regions. We have found this measurement to be highly reproducible, simple for the patient to repeat, unaffected by fluctuations in ambient NO concentration and perhaps more representative of $\mathrm{NO}$ in the periphery. ${ }^{22}$ It allows quick and easy recording of repeated measurements with minimal effort from the patient. The wide range in the measured exhaled NO values using end tidal value is comparable to that using the single deep and slow breath method, but was much easier on the patient. There is no compelling reason to suggest that either method is superior in terms of clinical relevance but NOet measurement is much simpler, not subject to errors due to lack of patient cooperation, less stressful for the patients and arguably offers a more balanced and uniform measurement of exhaled NO. The patients in this study may have not been sick enough to exhibit a substantial increase in exhaled NO, but also perhaps, the number maybe too small to make definite conclusions. Nevertheless, even with such small group of patients, with mild respiratory disease, there was clear difference in airway reactivity between responders and nonresponders and yet a marginal difference in NOet, whether expressed inppb or in $\mathrm{nmol} / \mathrm{min}$.

\section{Conclusion}

In summary, although not always explicitly stated, the interest in exhaled NO measurement reflects the desire to use such a measurement in asthma patients as adjunct or as replacement to current methods. We found that using the average end expiratory NO value during normal breathing was far simpler and more robust than the single deep and slow exhalation as suggested by the ATS guidelines in 2005. The simple measurement of end tidal NO is easily repeatable, unbiased by variation in flow rate and unaffected by patient cooperation. Our results are consistent with some published data and do not support the notion of a clinically revealing relationship between exhaled nitric oxide and bronchial reactivity.

\section{Acknowledgements}

None.

\section{Conflict of interest}

The author declares no conflict of interest.

\section{References}

1. Alving K, Weitzberg E, Lundberg JM. Increased amount of nitric oxide in exhaled air of asthmatics. Eur Respir J. 1993;6(9):1368-1370.

2. Kharitonov SA, Yates D, Robbins RA, et al. Increased nitric oxide in exhaled air of asthmatic patients. Lancet. 1994;343(8890):133-135.

3. Massaro AF, Gaston B, Kits D, et al. Expired nitric oxide levels during treatment of acute asthma. Am J Respir Crit Care Med. 1995;152(2):800-803.

4. Donohue JF, Jain N. Exhaled nitric oxide to predict corticosteroid responsiveness and reduce asthma exacerbation rates. Respir Med. 2013;107(7):943-952.

5. Gaston B, Drazen JM, Loscalzo J, et al. The biology of nitrogen oxides in the airways. Am J Respir Crit Care Med. 1994;149(2 pt 1):538-551.

6. Haccuria A, Michils A, Michiels S, et al. Exhaled nitric oxide: a biomarker integrating both function and airway inflammation changes. $J$ Allergy Clin Immunol. 2014;134(3):554-559.

7. Robbins RA, Barnes PJ, Springall DR, et al. Expression of inducible nitric oxide synthase in human bronchial epithelial cells. Biochem Bio phys Res Commun. 1994;203:209-18.

8. Dupont LJ, Rochette F, Demets MG, et al. Exhaled nitric oxide correlates with airway hyper responsiveness in steroid-naive patients with mild asthma. Am J Respir Crit Care Med. 1998;157(3 pt 1):894-898.

9. Yates DH, Kharitonov SA, Robbins RA, et al. Effect of a nitric oxide synthase inhibitor and a glucocorticosteroid on exhaled nitric oxide. $\mathrm{Am}$ J Respir Crit Care Med. 1995;152(3):892-896.

10. Bjermer L, Alving K, Diamant Z, et al. Current evidence and future research needs for FeNO measurement in respiratory disease. Respiratory Medicine. 2014:108(6):830-841.

11. Pedrosa M, Cancelliere N, Barranco P, Lópe Carrasco V, et al. Usefulness of exhaled nitric oxide for diagnosing asthma. J Asthma. 2010;47(7):817-821. 
12. Taylor DA, McGrath JL, O'Conner BJ, et al. Allergen-induced early and late asthmatic responses are not affected by inhibition of endogenous nitric oxide. Am J Respir Crit Care Med. 1998;158(1):99-106.

13. ATS Recommendations for standardized procedure for the on-line and offline measurement of exhaled nitric oxide and nasal nitric oxide in adults and children. Official Statement of the ATS was adopted in 1999. Am J Respir Crit Care Med. 1999;160:2104-2117.

14. ATS/ERS recommendations for standardized procedure for the online and offline measurement of exhaled lower respiratory nitric oxide and nasal nitric oxide. Am J Respir Crit Care Med. 2005;171:912-930.

15. Sverrild A, Malinovschi A, Porsbjerg C, et al. Predicting airway hyperreactivity to mannitol using exhaled nitric oxide in an unselected sample of adolescents and young adults. Respir Med. 2013;107(1):150-152.

16. Cirillo I, Ricciardolo FL, Medusei G, et al. Exhaled nitric oxide may predict bronchial hyperreactivity in patients with allergic rhinitis. Int Arch Allergy Immunol. 2013;160(3):322-328.

17. Manso L, Madero MF, Ruiz García M, et al. Comparison of bronchial hyper responsiveness to methacholine and adenosine and airway inflammation markers in patients with suspected asthma. J Asthma. 2011;48(4):335-340.

18. Guan WJ, Shi X, Jiang CY, et al. Responsiveness to methacholine but not leukotriene D4, correlates with fractional exhaled nitric oxide in asthma. Clin Respir J. 2014.

19. Prieto L, Gutierrez V, Uixera S, et al. Concentration of exhaled nitric oxide in asthmatics and subjects with allergic rhinitis sensitized to the same pollen allergen. Clin Exp Allergy. 2002;32(12):1728-1733.

20. Nickels A, Parker K, Scanlon P, et al. The role of a positive exhaled nitric oxide in evaluating the pulmonary patient:exhaled nitric oxide versus methacholine challenge? Chest. 2014;145 (suppl 3):467A.

21. Deykin A, Halpern O, Massaro AF, et al. Expired nitric oxide after bronchoprovocation and repeated spirometry in patients with asthma. Am J Respir Crit Care Med. 1998;157(3 pt 1):769-775.

22. Hakim TS, Cremona G, Camporesi EM. Measurement of exhaled nitric oxide using end tidal value during normal breathing. J Pulmon Respir Med. 2014;4:219.

23. Silkoff PE, McClean PA, Slutsky AS, et al. Marked flow-dependence of exhaled nitric oxide using a new technique to exclude nasal nitric oxide. Am J Respir Crit Care Med. 1997;155(1):260-267.

24. Giovannini M, Valli M, Ribuffo V, et al. Relationship between Methacholine Challenge Testing and exhaled nitric oxide in adult patients with suspected bronchial asthma. Eur Ann Allergy Clin Immunol. 2014;46(3):109-113.

25. Demange V, Bohadana A, Massin N, et al. Exhaled nitric oxide and airway hyper responsiveness in workers:a preliminary study in lifeguards. BMC Pulm Med. 2009;9:53.
26. Henriksen AH, Lingaas HT, Sue CM, et al. Combined use of exhaled nitric oxide and airway hyper responsiveness in characterizing asthma in a large population survey. Eur Respir J. 2000;15(5):849-855.

27. Garnier P, Fajac I, Dessanges JF, et al. Exhaled nitric oxide during acute changes of airways calibre in asthma. Eur Respir J. 1996;9(6):1134 1138 .

28. Silvestri M, Spallarossa D, Battistini E, et al. Dissociation between exhaled nitric oxide and hyper responsiveness in children with mild intermittent asthma. Thorax. 2000;55(6):484-488.

29. Ricciardolo FL, Timmers MC, Sont JK, et al. Effect of bradykinin on allergen induced increase nitric oxide in asthma. Thorax. 2003;58:840 845

30. Beretta E, Tana F, Grasso GS, et al. Regional differences in bronchia reactivity assessed by respiratory impedance. Respir Physiol Neurobiol. 2014;192:23-29.

31. Amirav I, Kramer SS, Grunstein MM, et al. Assessment of methacholine-induced airway constriction by ultrafast high-resolution computed tomography. J Appl Physiol. 1993;75(5):2239-2250.

32. Farrow CE, Salome CM, Harris BE, et al. Airway closure on imaging relates to airway hyper responsiveness and peripheral airway disease in asthma. J Appl Physiol. 2012;113(6):958-966.

33. Downie SR, Salome CM, Verbanck S, et al. Effect of methacholine on peripheral lung mechanics and ventilation heterogeneity in asthma. $J$ Appl Physiol. 2013;114(6):770-777.

34. Verbanck S, Kerckx Y, Schuermans D, et al. Effect of airways constriction on exhaled nitric oxide. J Appl Physiol. 2008;104(4):925-930.

35. Downie SR, Salome CM, Verbanck S, et al. Ventilation heterogeneity is a major determinant of airway hyper responsiveness in asthma, independent of airway inflammation. Thorax. 2007;62(8):684-689.

36. Affonce DA, Lutchen KR. New perspectives on the mechanical basis for airway hyperreactivity and airway hypersensitivity in asthma. $J \mathrm{Appl}$ Physiol. 2006;101(6):1710-1719.

37. Sethi JM, White AM, Patel SA, et al. Bronchoprovocation testing in asthma: effect on exhaled monoxides. J Breath Res. 2010;4(4):1-7.

38. Sanna A, Kurtansky A, Venter C, et al. Bronchodilator effect of inhaled nitric oxide in healthy men. Am J Respir Crit Care Med. 1994;150:17021704

39. Parker CC, Bilbo RE, Reed CE. Methacholine aerosol as a test for bronchial asthma. Arch Intern Med. 1965;115:452-461.

40. Hogman M, Frostell CG, Hedenstrom H, et al. Inhalation of nitric oxide modulates adult human bronchial tone. Am Rev Respir Dis. 1993;148(6 pt 1):1474-1478.

41. Townley RG, Bewtra AK, Nair NM, et al. Methacholine inhalation challenge studies. J Allergy Clin Immun. 1979;64(6):569-574. 